\title{
Hypersexuality Addiction and Withdrawal: Phenomenology, Neurogenetics and Epigenetics
}

\author{
Kenneth Blum ${ }^{1}$, Rajendra D. Badgaiyan ${ }^{2}$, Mark S. Gold 3 \\ 1. Department of Psychiatry, McKnight Brain Institute , University of Florida, 2. Department of Psychiatry, \\ and Laboratory of Advanced Radiochemistry, University of Minnesota ,School of Medicine, Minneapolis , \\ MN., USA 3. Departments of Psychiatry \& Behavioral Sciences, Keck School of Medicine of USC, Los \\ Angeles, CA, USA
}

$\square$ Corresponding author: Kenneth Blum, drd2gene@gmail.com

Disclosures can be found in Additional Information at the end of the article

\section{Abstract}

Hypersexuality is now part of the DSM-V and has been defined as abnormally increased sexual activity. Epidemiological and clinical studies have shown that this non-paraphilic condition consists of "excessive" sexual behaviors and disorders accompanied by personal distress and social and medical morbidity. Hypersexual disorder is conceptualized as primarily a nonparaphilic sexual desire disorder with impulsivity. Pathophysiological perspectives include dysregulation of sexual arousal and desire, sexual impulsivity, sexual addiction, and sexual compulsivity. The nucleus accumbens, situated within the ventral striatum, mediates the reinforcing effects of drugs of abuse, such as cocaine, alcohol, nicotine, and food as well as music. Indeed, it is believed that this structure mandates behaviors elicited by incentive stimuli. These behaviors include natural rewards like feeding, drinking, sexual behavior, and exploratory locomotion. An essential rule of positive reinforcement is that motor responses will increase in magnitude and vigor if followed by a rewarding event. Here, we are hypothesizing that there is a common mechanism of action (MOA) for the powerful effects drugs, music, food, and sex have on human motivation. The human drive for the three necessary motivational behaviors "hunger, thirst, and sex" may all have common molecular genetic antecedents that, if impaired, lead to aberrant behaviors. We hypothesize that based on a plethora of scientific support hypersexual activity is indeed like drugs, food, and music that activate brain mesolimbic reward circuitry. Moreover, dopaminergic gene and possibly other candidate neurotransmitter-related gene polymorphisms affect both hedonic and anhedonic behavioral outcomes. There is little known about both the genetics and epigenetics of hypersexuality in the current literature. However, we anticipate that future studies based on assessments with clinical instruments combined with genotyping of sex addicts will provide evidence for specific clustering of sexual typologies with polymorphic associations. The authors are also encouraging both clinical and academic scientists to embark on research using neuroimaging tools to examine natural dopaminergic agonistic

Received 07/24/2015

Review began 07/24/2015 Review ended 07/26/2015 Published 07/27/2015

\section{(c) Copyright 2015}

Blum et al. This is an open access article distributed under the terms of the Creative Commons Attribution License CC-BY 3.0., which permits unrestricted use, distribution, and reproduction in any medium, provided the original author and source are credited.
Categories: Psychiatry, Neurology, Genetics

Keywords: neurogenetics, epigenetics, reward deficiency syndrome, compulsivity, hypersexuality disorder

\section{Introduction And Background}

Certainly, hypersexual behavior has been documented within clinical and research settings over the past decade [1]. Benjamin Rush, a physician and founding father of the United Sates clinically 
documented excessive sexual behaviors [2]. Richard von Krafft-Ebing, a 19th-century Western European pioneer sexologist, and Hirshfeld in 1948 both continued the work [3-4]. The basic tenant of these investigators suggested that hypersexuality constituted persistent socially deviant sexual behavior(s) in both males and females with excessive sexual appetite being maladaptive. In 1975, Stroller characterized the condition as Don Juanism [5]. In 1969, Allen suggested satyriasis for males and nymphomania in females supported by Ellis and Sagarin [6-7]. Since DSM-5 does not currently include "hypersexuality," we hereby encourage continued research into this very important area and applaud the major accomplishments of Kafka, Reid, Bancroft and even the World Health Organization among others [8-11].

\section{Review}

\section{Literature methodology}

The Medline database, as of July 12, 2015, was used to perform an internet-based literature search. The following terms were included: hypersexual (170), hypersexuality (479), sexual addiction (1,652), sex addict $(1,842)$, sexual impulsivity (989), compulsive sexual (946), compulsive sex $(1,512)$, sexual compulsion (782), paraphilia-related disorder (234), and excessive sexual (857). Since this article is a brief review rather than a meta-analysis, it is based on a representative selection of these studies that have relevance to the subtopics covered.

\section{Definition of sexual addiction}

Sexual addiction is defined as any compulsive sexual behavior that interferes with normal living and causes severe stress on the family, friends, loved ones, and one's work environment. Sexual addiction has been called sexual dependency, hypersexuality, and sexual compulsivity. By any name, it is a compulsive behavior that completely dominates the addict's life. Sexual addicts make sex a priority more important than family, friends, and work. Sex becomes the organizing principle of addict's lives. They are willing to sacrifice what they cherish most to preserve and continue their unhealthy behavior [12]. Hypersexual desire has been delineated as desire based on a lifetime assessment of the frequency of sexual behavior and time spent in associated sexual fantasies. In males, an evaluation of hypersexual desire was defined by Kafka and Hannen [13] as the highest sustained period (at least six months minimum duration) of persistently enacted sexual behavior (total sexual outlet/week after age 15). In fact, a longitudinal history of hypersexual desire, operationally defined as above, was identified in $72-80 \%$ of males seeking treatment for paraphilias and paraphilia-related disorders.

\section{Hypersexuality and gender differences}

It is well established that in the human sexual community and literature sexual desire is capitulated as the presence of sexual fantasies, activities or urges, and motivation by the human to engage in sexual behaviors. There are both internal and external relevant cues [14]. Evolutionary theory proponents have argued that men and women have different agendas when it comes to sexual activity [15]. Numerous studies reveal distinct differences between males and females. Males have increased sexual fantasy [16], increased frequency of masturbation [17], increased propensity for externally generated visual sexual arousal [18], permissive attitudes toward casual sex [19], ease of arousal [20], and intrinsic motivation [21]. In contrast, females show a different sexual landscape with sexual motivation, sexual arousal, and sexual behavior being shaped by evolutionary factors [22] and greater biological, emotional, and temporal investment in reproduction and child-rearing [23]. Females are less vulnerable to hypersexuality [24] and adapted to foster affiliative relationships and longer-term partner commitment [25]. While sexual addiction is estimated to afflict up to $3 \%$ to $6 \%$ of the population, the clear understanding of the neurobiological antecedents are limited [26] as well as clinical assessments [27]. We encourage further reading on sexual compulsion, attachment and sexual orientation [28], and gender differences in responses to sexual stimuli [29-30]. 
It is noteworthy that Kafka and Hennen [13] found that the mean age of onset of persistent hypersexual behavior was $18.7 \pm 7.2$ years in sexually active men and the age range of onset of hypersexual behavior was age $7-46$. The average duration of this highest consistently maintained frequency of sexual appetitive behavior was $12.3 \pm 10.1$ years. However, the mean age of these active sexual males being hypersexual that sought treatment was $37 \pm 9$ years. Hanson, et al. also evaluated hypersexuality in offenders and found that low offenders had lower recidivism rates than high-risk offenders [31].

\section{Hypersexuality and co-morbid substance abuse}

There is a high co-morbidity between hypersexual disorder (now part of DSM-5) and other addictions, such as substance use disorder [32-33]. Specifically, Garcia and Thibaut proposed that the phenomenology of excessive non-paraphilic sexual disorder should be classified as an addictive behavior, rather than an obsessive-compulsive, or an impulse control disorder [34]. They correctly point out that the criteria are quite close to those of addictive disorders as also proposed by others [35]. These investigators have provided the impetus to include hypersexual disorder in the DSM-5. Drugs of abuse, rock ' $n$ ' roll, and sex are co-occurring, and entire festivals have been built around these combinations from Woodstock to the present.

The literature reveals that users of methamphetamine report that this stimulatory drug increases sexual desire, especially risky behavior. However, amphetamine has been shown to reduce the sexual activity of female rats. With this in mind, Holder, et al. evaluated the role of methamphetamine in female rats [36]. They found that, on the contrary, methamphetamine facilitated female sexual behavior, and this effect is due to enhancement of dopaminergic transmission and even possible neurotransmission due to the combination of ovarian hormones and methamphetamine. Specifically, they found an enhancement of sexual motivation coupled with activation of neuronal activity in the medial amygdala and ventromedial nucleus of the hypothalamus.

Moreover, scientists from the Netherlands have studied the co-morbidity of substance abuse in self-identified swingers [37]. In this study, Spauwen, et al. concluded that $79 \%$ of swingers reported recreational drug use (including alcohol and use of erectile dysfunction drugs); $46 \%$ of them reported multiple drug use. In fact, recreational drug use (excluding alcohol and erectile dysfunction drugs) was significantly linked with high-risk sexual behaviors in men and women. Also, drug use was independently associated with sexually transmitted infections (STI) in female swingers, especially those who participate in group sex.

Castelo-Branco, et al. reported that young adult women perceive that sexuality is an important part of their life but not a primary concern (77.6\%) [38]. They also reported that alcohol removes the barriers to having sex (62.3\%). Importantly, they also found that alcohol abuse was a predictive variable in enhancing risky behaviors independent of the age of the female.

It is noteworthy that Jia, et al. reported dangerous sexual behaviors among psychostimulant and heroin abusers, including multiple sexual intercourse, casual sexual partners, homosexual partners, and never or occasionally practicing safe sex [39].

Our main tenant is that drugs, such as methamphetamine, cocaine, heroin, and alcohol, can stimulate sexual desire in non-addicts. In addicts, it is quite different; the same drugs can cause anhedonia on a chronic basis. However, post-addiction during the recovery phase in many cases aphrodisiac-like behaviors have been observed.

\section{Hypersexuality and withdrawal}

A PubMed search (7-19-15) using the term "hypersexuality and withdrawal symptoms" resulted 
in only five articles, none of which described "withdrawal symptomatology". However, an alternative search using the terms "high sexual activity withdrawal symptoms" resulted in 25 listed articles.

Addicts in recovery report increases in eating and an appetite drive for certain foods and abuse of cigarettes during prolonged abstinence. Weight gain has also been demonstrated and documented in recently and prolonged abstinent animals and humans [39]. Bruijnzeel made the interesting observation that acute opiate withdrawal can result in spontaneous orgasms [40]. Importantly, in the article, Bruijnzeel proposed that withdrawal symptomatology from drugs and possibly chronic intensive sexual activity may be due to the unopposed function of kappa opioid receptor signaling that inhibits the release of dopamine while increasing norepinephrine in brain reward circuits.

The papers in the literature suffered from a lack of rigor regarding acute and prolonged withdrawal and abstinence confirmed by urine testing. Clinical treatment programs have increasingly moved from treating both genders to isolating the two sexes, providing genderspecific treatment programs. They also offer education to address the early and prolonged increases in sexual interest and activity, and the relationship of recovery to food and overeating.

Hypersexuality-induced withdrawal symptoms have been reported by some investigators with varying degrees of severity and co-morbid substance abuse [41-45]. As a result of this search, we did not find a single paper describing actual withdrawal symptoms associated with abstinence from active sexual encounters. Most of the papers cited involved the effects of withdrawal from drugs of abuse, such as opioids, nicotine, amphetamines, and cocaine, that can impair sexual activity.

\section{Hypersexuality and neurogenetics}

A PubMed search (7-19-15) revealed only six listed papers using the term "genes and hypersexuality" mostly focusing on articles related to Kleine-Levin syndrome (KLS), a very rare disease whereby hypersexuality could last up to 27 years. In one study, it was found that an immune responsive HLA-DQB1, DQB1 *0602 was detected in significant quantities in patients with KLS and could elevate the risk of KLS [46-47].

However, when we used the terms "sexual activity and genes," 2,826 articles were listed, and we provide a brief synopsis of a few important neurogenetic aspects. It is our hypothesis that both hedonic and anhedonic behaviors are outcomes in part of an individual's risk alleles for these behaviors and that treatment consists of appropriately targeting these identified

polymorphisms. Moreover, treatment response also depends on these risk alleles and provides an important rationale for pharmacogenetic testing and pharmacogenomic/nutrigenomic solutions.

Following the controversial initial finding by Blum, et al. in 1990 of the first evidence for an association between the DRD2 A1 allele and severe alcoholism, there have been 3,938 articles in PubMed (7-19-15) [48]. The studies cover the psychiatric gene polymorphism, the DRD2 A1 allele, and associated behaviors and physiology. There is, however, a paucity of data linking sexual activity to this and other related genes despite the overwhelming evidence for mesolimbic activation, especially in dopaminergic pathways and neuronal loci related to sexual stimuli and activity. It is noteworthy that Blum and Noble correctly classified the DRD2 gene as a generalized reward gene responsible for all reward deficiency syndrome (RDS) behavior. In fact, using Bayesian theorem analysis carriers of the Taq A1 allele will, over their lifetime, have a 74\% chance that they will rendezvous with one or more reward deficiency syndrome (RDS) behavior [49]. 
The first association of any gene polymorphism and sexual activity did not occur until 1999 when Miller, et al. evaluated some dopaminergic genes [50]. The basic finding is that the dopaminergic system in the brain seems to play a major role in the regulation of sexual behavior. The relationship between genes for the D1, D2, and D4 dopamine receptors and age at first sexual intercourse (AFSI) was examined in a sample of 414 non-Hispanic, European-American men and women. A significant association was observed between a DRD2 allele and AFSI and an even stronger association when the DRD2 allele was interacted with a DRD1 allele. A constrained regression model was constructed predicting AFSI using sex and a group of nine psychosocial variables as predictors. Adding the DRD2 and the DRD2-by-DRD1 predictors to this model increased the explained variance by $23 \%$ and $55 \%$, respectively. The fact that these findings suggest a stronger association among males than among females is in agreement with the recent work of others showing higher sexual stimuli response in males than in females [51]. So maybe "men are from Mars and females from Venus" and this may even be true for cocaine abuse [52]. Specifically, both preclinical and clinical studies have shown sexually dimorphic patterns in behavioral responses to cocaine in all phases of the cocaine addiction process (induction, maintenance, and relapse). Thus, a clear picture is emerging which suggests that the biological basis of sex-specific differences in cocaine addiction. These differences result from the disparate regulation of the CNS by male and female gonadal hormones and may be predicted by the presence of DRD2 gene polymorphisms [53]. Moreover, it is known that genetic associations between COMT and various psychiatric phenotypes frequently show differences between men and women. These include the functional Val (158)Met polymorphism in COMT being associated with obsessive-compulsive disorder in men and with anxiety phenotypes in women. Additionally, the Val (158)Met polymorphism in COMT has a greater impact on cognitive function in boys than girls [54].

Miller, et al. did not find an association of the polymorphisms linked to the DRDD4 gene and age of first sexual intercourse [50]. However, others found a significant association in certain ethnic groups. Specifically, their analysis of the polymorphisms in DRD4 indicates that those with any 3R genotype experienced a risk of first sexual intercourse higher than those with other (or any $4 R)$ genotype in the all-ethnicities $(n=2,552)$. Interestingly, the risk of first sex does not differ between the two genotypes in the African-American sample, raising the question of cultural upbringing [55].

The sexual experience, like repeated drug use, produces long-term changes, including sensitization in the nucleus accumbens (NAc) and dorsal striatum. Bradley, et al. using microarray analysis to study hamsters found for the first time that the sexual experience in either male or female animals differentially up or downregulates mRNA expression of a series of genes in the NAc [56]. They found that in comparison with sexually naive animals, sexually experienced hamsters receiving a stimulus male on Week 7 exhibited an increase in a large number of genes. Conversely, sexually experienced female hamsters not receiving a stimulus male on Week 7 exhibited a reduction in the expression of many genes. According to the authors, this first ever gene profiling in female hamsters may provide an insight into the mechanisms by which both behaviors (sex) and drugs of abuse induce long-term changes in the mesolimbic and nigrostriatal dopamine pathways.

Bipolar electrodes, implanted bilaterally in the lateral hypothalamus and substantia nigraventral tegmental area, stereotaxically were used to provide chronic self-stimulating reward experiences similar to sexual behavior. This type of stimulation has been found to induce a significant increase in the number of synapses in the CA3 region of the hippocampus and the molecular layer of the motor cortex in rats. In essence, chronic brain stimulation induced longterm potentiation (LTP), which is known to increase new synaptic connections [57]. A single exposure to cocaine in naive animals is sufficient to trigger sustained changes in ventral tegmental area (VTA) glutamatergic synapses that resemble activity-dependent LTP in other brain regions. This cocaine-induced LTP appears to be mediated via dopamine $\mathrm{D}_{5}$ receptor 
activation of N-methyl-D-aspartate (NMDA) receptors and to require protein synthesis [58], once again supporting our premise proposed here that drugs and sex may have common neurochemical substrates.

Empirical research has revealed a positive relationship between the number of sex partners and involvement in antisocial behaviors. Most attempts to explain this association have taken an evolutionary perspective. From the evolutionary perspective, the same traits, for example, impulsiveness, shortsightedness, and aggressiveness, that are related to a large number of sex partners are also related to criminal involvement. However, there is also reason to believe that the covariation between sex partners and crime behaviors can be partially explained by a common genetic pathway, where genes that are related to sex partner numbers are also related to antisocial conduct. Using the above-described rationale, Beaver et al. found a strong positive association between sex partners and antisocial behavior and polymorphisms of the dopamine transporter gene (DAT1) explains variation in both numbers of sexual partners and criminal conduct for males [59]. The polymorphic effect of the DAT1 gene and the number of sexual partners may be due an association found between certain polymorphisms and male premature penile ejaculation. Carriers of the 10R10R genotype had scores indicating a lower threshold to ejaculate on each of the indicators compared to the combined 9R9R/9R10R (9R higher activity lower dopamine availability) carrier group [60]. Polymorphisms of the DAT1 gene, specifically the 10R10R genotype, has been found in juvenile delinquents attending the Brown School (San Marcos, Texas) for pathological aggressive behaviors, including anti-social behavior [60]. A positive correlation of both DRD2 and the DAT1 polymorphisms were observed with pathological violence in adolescents in a blinded clinical trial. Moreover, though initially conceptualized as resulting from peer imitation of child-onset or life-course-persistent youth, there is mounting evidence from twin studies that adolescent-onset or adolescent-limited antisocial behavior may also be genetically influenced. Burt and Mikolajewski not only confirmed these findings with the DAT1 gene but extended these findings to include the His452Tyr variant of the gene encoding the 5-HT2A receptor as well [62]. More recently, Jóźków, et al. reported an association between the sexual dimension of aging males' symptoms (AMS) and genetic variants of 5-HTR1B G861C [63]. Moreover, Sales, et al. found through multivariable logistic regression analysis, an interaction between abuse and the 5-HTTLPR group was significantly associated with non-change status, along with partner communication frequency scores at follow-up [64]. Having a history of abuse was significantly associated with greater odds of non-change in condom use post-intervention for only those with the s allele.

It is known that polymorphisms in noncoding regions of the vasopressin 1a receptor gene (Avpr1a) are linked to socio-emotional characteristics in humans, chimpanzees, and voles, and may due to a site-specific variation in gene expression. According to Barrett, et al., the socially monogamous prairie vole offers a unique opportunity to study the neurobiology of monogamy [65]. In fact, vasopressin 1a receptor (V1aR) signaling is necessary for the formation of the pair bond in males. Interestingly, social prairie voles exhibit greater V1aR binding in the reward processing ventral pallidum than do asocial voles of the same genus. Barrett, et al. found that down-regulation of pallidal V1aR density resulted in a significant impairment in the preference for a mated female partner and a reduction in anxiety-like behavior in adulthood [65]. Other work by Garcia, et al. revealed that individuals with at least one 7-repeat allele (7R+) of the DRD4 report a greater categorical rate of promiscuous sexual behavior, including having ever had a "one-night stand", and report a more than 50\% increase in instances of sexual infidelity [66].

Importantly, Daw and Guo reported that individuals carrying the genotypes DRD2*A1/A2, DRD2*A2/A2, DAT1*9R/10R, and MAOA*2R/ are associated with higher odds of unprotected sexual intercourse than other genotypes at these loci [67]. The DRD2 associations apply to both men and women, whereas the other links apply to women only.

Finally, Emanuele, et al. reported a significant association between the DRD2 TaqI A genotypes 
and "Eros" (a loving style characterized by a tendency to develop intense emotional experiences based on the physical attraction to the partner), as well as between the C516T 5HT2A

polymorphism and "mania" (a possessive and dependent romantic attachment, characterized by self-defeating emotions) [68].

\section{Epigenetics and sexual activity}

A review of the literature reveals that a number of recent articles point out the importance of epigenetic effects on sexual activity. For example, Matsuda reviewed the epigenetic changes of the estrogen receptor $\alpha(E R \alpha)$ and influence on sociosexual behavior [69]. In fact, alteration of ER $\alpha$ gene activity mediated by epigenetic mechanisms, such as histone modifications and DNA methylation, alters one's sexual behaviors. In terms of homosexuality, Rice, et al. developed a model that may explain the canalization (conversion) homosexuality sexual development [70]. They explain that this model is based on epigenetic marks laid down in response to the XX vs. XY karyotype in embryonic stem cells. Accordingly, these marks boost sensitivity to testosterone in $\mathrm{XY}$ fetuses and lower it in XX fetuses, thereby canalizing sexual development. It has been postulated that a subset of these converting epigenetic marks quantitatively may carry over trans-genetically, and could lead to mosaicism for sexual development in opposite-sex offspring-the homosexual phenotype.

In the socially monogamous prairie vole (Microtus ochrogaster), mating induces enduring pairbonds that are initiated by partner preference formation and regulated by a variety of neurotransmitters, including oxytocin, vasopressin, and dopamine. Work by Gundersen [71] and Wang, et al. [72] suggests that histone deacetylase could facilitate partner formation in female prairie voles that may have relevance to humans. Specifically, Wang, et al. found that histonedeacetylase-inhibitors-sodium butyrate and trichostatin A (TSA) enhanced partner preference formation in female prairie voles [72]. This partner preference formation was associated with an upregulation of oxytocin receptor (OTR, oxtr) and vasopressin V1a receptor (V1aR, avpr1a) in the NAc, through an increase in histone acetylation at their respective promoters.

There is interest growing evidence that indicates that females actively engage in polyandry either to avoid genetic incompatibility or to bias paternity in favor of genetically superior males. There is the possibility that selection of superior male fitness may be due epigenetic effects. According to Zeh and Zeh, unlike DNA sequence-based variation, epigenetic variation can be strongly influenced by environmental and stochastic effects experienced during the lifetime of an individual [73]. They suggest that epigenetic variation may be important for the post-copulatory sexual selection and may account for findings linking sperm competitive ability to offspring fitness.

\section{Genetic and meme evolution: Human procreation}

Eysenck proposed a positive correlation between extraversion and intensified sexual behavior and between neuroticism and problems in sexual behavior (anti-social behavior). An earlier study with married people did not show any of these correlations. It was hypothesized that this connection exists only for unmarried persons not engaged in long-lasting relationships because the quality of the relationship determines the sexual interaction. Within a sample of young unmarried men, there was a positive correlation between extraversion and items in which the person described earlier sexual activity with more individuals and in higher frequency. No correlation was found with neuroticism. There were also slight correlations with other personality and social attitude scales. Because of the correlation with an acting-out personality scale, the findings were interpreted from a social-psychological perspective. In today's society, the young male is expected to take the initiative in a sexual interaction that an extraverted young male can realize better than one who is introverted [74]. This perspective is in direct agreement with Richard Brodie's idea about selfish genes of the mind [75]. From the DNA's point 
of view, of course, anthropologists would agree "we're still here for one reason only; to go forth and multiply." While evolutionary advances are slow, one step every 20 years or so, compared with "meme evolution, an idea mutates in the time it takes to read a sentence." Our brains have nothing to do with genetic evolution except as it is related to smart people having fewer babies. In fact, if there are genes that give people the tendency to take on memes that limit their number of offspring, they will die out in a few generations in favor of genes that give people a tendency to acquire children. Unfortunately, a number of studies suggest Homo sapiens over the last 42,000 years have lowered their IQs due to selective mating [76].

Extraordinarily, it turns out that since extraversion is linked to increased sexual activity especially in males, quantitative geneticist estimates the heritability of the extraverted personality to be around $40-60 \%$. Smillie and associates studied and found that one copy of the DRD2 gene A1 allele was associated with significantly higher extraversion [77]. This association raises an interesting question in terms of human procreation. Comings suggested that because of their marked effect on reproductive behavior, learning disorders and other impulsive, compulsive, aggressive, and addictive disorders those carriers of the DRD2 A1 have the potential to cause progressive and permanent changes in the frequency of the DRD2A1 allele "leading to the genetic meltdown of the species" [78].

In his book, Comings provides evidence that people with addictive-disruptive behaviors have children earlier, and this impacts the selection of addiction genes like the DRD2 A1 allele [79]. He suggests that individuals carrying this disruptive risk allele will have children let's say at 20 years of age and individuals without this allele will have children at 25 years. As a result, the mutant gene will reproduce faster, namely, every 20 years while the normal form of the gene will reproduce every 25 years. The ratio of $25 / 20$ is 1.25 . Thus, the rate at which a gene that has a 1.25 -fold selective advantage will increase in frequency from generation to generation. A difference of five years in the age of mothers or fathers when they have their first children is sufficient to result in a significant and relatively rapid selection for genes carried by group initiating childbearing at an earlier age. Increases in some RDS behaviors have been documented from 1955 to the present. These increases include adolescent behavior syndrome (drugs, sex, teen pregnancies, and delinquent behaviors, smoking), conduct disorder, crime, drug abuse, alcoholism, unprotected sexual behavior, unwed mothers, welfare, school expelled, and school dropouts, as well a concomitant decrease in IQ [80]. These results are based on the Berkeley Study utilizing longitudinal data from the Child Health and Developmental Studies and the National Longitudinal Surveys of Youth or NLYS [81]. Utilizing this information, Comings predicted that from 1955 to 2015 there will be a doubling of the frequency of, for example, the DRD2 A1 allele, therefore increasing the prevalence of RDS behaviors, including precocious sexual intercourse [50]. We encourage a follow-up of this interesting prediction.

We are proposing hypersexuality disorder as a subtype of RDS sharing characteristics with substance and non-substance addictive behaviors with its clinical expression being partly affected by both genetics and epigenetics. Although untested at this time, we also propose shortterm FDA-approved medication-assisted treatments (MAT) favoring blocking dopamine function followed by gentle activation of dopaminergic pathways leading to long-term dopamine homeostasis. The latter could be accomplished by some modalities that may help in recovery. They include dopamine agonist therapy - nutraceuticals (KB220z), the 12 Step program and tradition, holistic treatment, cognitive behavioral therapy (CBT), and trauma relief therapy (TRT) as well as dopamine boosting activities and foods (Figure 1) [82]. 


\section{Mapping Hypersexuality Disorder}

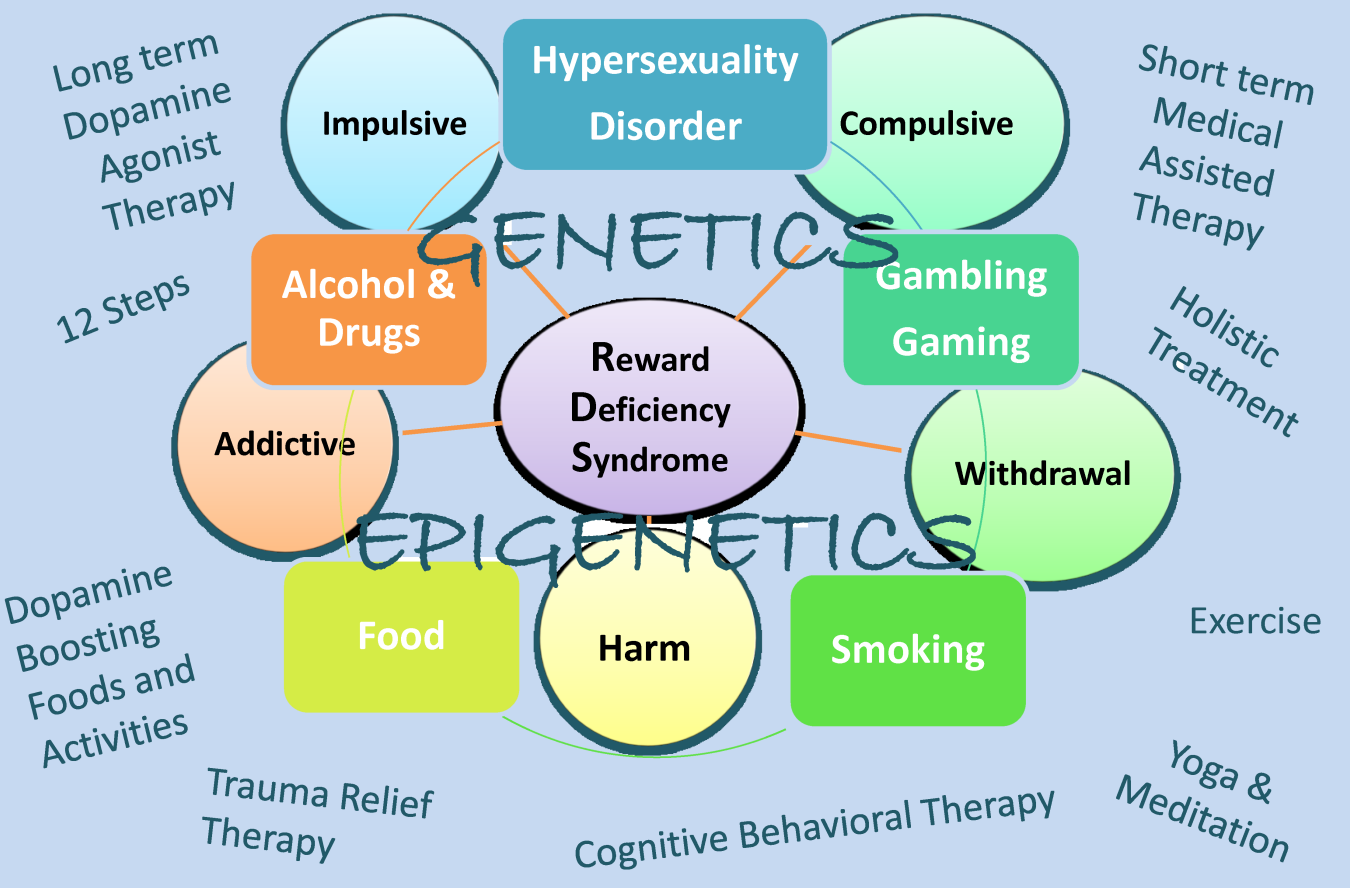

\section{FIGURE 1: A descriptive map of Hypersexuality Disorder as a subtype of RDS}

The figure illustrates interactive neurogenetic and epigenetic effects. Both short-term dopamine blocking and long -term "dopaminergic - homeostasis" -based treatments and dopamine boosting therapies and daily activities are listed. Circles indicate RDS characteristics and boxes indicate RDS behaviors.

\section{Conclusions}

While we firmly believe that it is important that hypersexuality disorder is included in the DSM5 , we are somewhat perplexed that so little is known about this disorder in terms of neurogenetics and epigenetics and even withdrawal symptomatology and overall phenomenology [83]. The prime take-home message is that we now encourage the scientific community to perform experiments, especially in the realm of neuroimaging and neurogenetics including epigenetics specific to genes, such as oxytocin -vasopressin-orexin - dopamine as well as other reward genes. Possibly this condition may benefit from treatment that targets reward gene polymorphisms to assist in promoting dopamine homeostasis [84-89]. A number of reviews by Joranby, et al. and Edge and Gold support common treatment opportunities related to shared neurochemical mechanisms in brain reward circuitry as espoused earlier in the RDS concept [9091].

\section{Additional Information}

\section{Disclosures}

This study did not involve human participants or tissue. This study did not involve animal subjects or tissue. Conflicts of interest: The authors have declared that no conflicts of interest exist except for the following: Payment/services info: Dr. Blum is the co-recipient of a grant 
from the Life Extension Foundation, Ft. Lauderdale, Fl., USA to Path Foundation, NYC, USA. Dr. Badgaiyan is supported by NIH 1R01NS07884. Financial relationships: Kenneth Blum declare(s) personal fees, a patent and royalties from Dominion Diagnostic LLC. Licence agreement for genetic testing. Kenneth Blum declare(s) non-financial support, royalties and stock/stock options from RDSS LLC. License agreement for Synaptamine . Kenneth Blum declare(s) personal fees, non-financial support and a patent from Victory Nutrition International ,LLC. license agreement for Brain Reward. Kenneth Blum declare(s) non-financial support and a patent from Malibu Beach Recovery Center . Consultant. Kenneth Blum declare(s) personal fees, non-financial support and a patent from Rivermend Health. Member Scientific Advisory Board. Mark S. Gold declare(s) non-financial support and a patent from Rivermend Health. Chairman Scientific Advisory Board. Intellectual property info: US patent no. 6,132,724; 6,955,873 issued. US PATENT APPLICATION 11/250,355; PCT /US2009/048074; PROVISIONAL 62,08,173.

\section{Acknowledgements}

The authors appreciate the expert edits and artwork design of Margaret A. Madigan.

\section{References}

1. Kor A, Fogel Y, Reid RC, Potenza MN: Should Hypersexual Disorder be classified as an addiction?. Sex Addict Compulsivity. 2013, 20:http://www.ncbi.nlm.nih.gov/pmc/articles/PMC3836191/. 10.1080/10720162.2013.768132

2. Rush B: Medical Inquiries and Observations upon the Disease of the Mind. Rush B (ed): Gryphon Editions Ltd., Birmingham, AL; (Original work published 1812) reviewed in 1979.

3. von Krafft-Ebing R: Psychopathia Sexualis. Klaf FS (ed): Stein and Day, New York; (original work published 1886) reviewed in 1965.

4. Hirshfeld M: Sexual anomalies: The origins, nature and treatment of sexual disorders . Hirshfeld M (ed): Emerson Books, New York; 1948.

5. Stroller RJ: Perversion: The erotic form of hatred . Pantheon Books, New York; 1975.

6. Allen CA: A textbook of psychosexual disorders. Oxford University Press, London; 1962.

7. Ellis A, Sagarin E: Nymphomania: A study of the oversexed woman . Gilbert Press, New York; 1964.

8. Kafka MP: What happened to hypersexual disorder?. Arch Sex Behav. 2014, 43:1259-1261. 10.1007/s10508-014-0326-y

9. Reid RC, Temko J, Moghaddam JF, Fong TW: Shame, rumination, and self-compassion in men assessed for hypersexual disorder. J Psychiatr Pract. 2014, 20:260-268.

10.1097/01.pra.0000452562.98286.c5

10. Bancroft J: Human Sexuality and Its Problems. Third edition . Elsevier, Oxford, England; 2009.

11. International Statistical Classification of Diseases and Related Health Problems, 10th Revision (2007). Accessed: July 23, 2015: http://apps.who.int/classifications/apps/icd/icd10online2007/.

12. Singer B, Toates FM: Sexual motivation. J Sex Research. 1987, 23:481-501. 10.1080/00224498709551386

13. Kafka MP, Hennen J: Hypersexual desire in males: are males with paraphilias different from males with paraphilia-related disorders?. Sex Abuse. 2003, 15:307-321. 10.1023/A:1025000227956

14. Buss DM, Schmitt DP: Sexual strategies theory: an evolutionary perspective on human mating . Psychol Rev. 1993, 100:204-232. 10.1037/0033-295X.100.2.204

15. Corbett-Detig RB, Hartl DL, Sackton TB : Natural selection constrains neutral diversity across a wide range of species. Psychol Bull . 1995, 13:e1002112.- 469-496. doi:

10.1371/journal.pbio.1002112

16. Laumann EO, Michael RT, Gagnon JH: A political history of the national sex survey of adults . Fam Plann Perspect. 1994, 26:34-38. 10.2307/2136095

17. Jones JC, Barlow DH: Self-reported frequency of sexual urges, fantasies, and masturbatory fantasies in heterosexual males and females. Arch Sex Behav. 1990, 19:269-79.

10.1007/BF01541552

18. Oliver MB, Hyde JS: Gender differences in sexuality: a meta-analysis. Psychol Bull. 1993, 114:29-51. 10.1037/0033-2909.114.1.29 
19. Okami P, Shackelford TK: Human sex differences in sexual psychology and behavior . Annu Rev Sex Res. 2001, 12:186-241. 10.1080/10532528.2001.10559798

20. Leitenberg H, Detzer MJ, Srebnik D: Gender differences in masturbation and the relation of masturbation experience in preadolescence and/or early adolescence to sexual behavior and sexual adjustment in young adulthood. Arch Sex Behav. 1993, 22:87-98. 10.1007/BF01542359

21. Fetterman AK, Kruger NN, Robinson MD: Sex-linked mating strategies diverge with a manipulation of genital salience. Motiv Emot. 2015, 39:99-103. 10.1007/s11031-014-9420-7

22. Basson R: Using a different model for female sexual response to address women's problematic low sexual desire. J Sex Marital Ther. 2001, 27:395-403. 10.1080/713846827

23. Andersen BL, Cyranowski JM, Aarestad S: Beyond artificial, sex-linked distinctions to conceptualize female sexuality: comment on Baumeister. Psychol Bull. 2000, 126:380-389. 10.1037//0033-2909.126.3.380

24. Knight RA, Sims-Knight JE: The developmental antecedents of sexual coercion against women: testing alternative hypotheses with structural equation modeling. Ann N Y Acad Sci. 2003, 989:72-85. 10.1111/j.1749-6632.2003.tb07294.x

25. Blum K, Werner T, Carnes S, Carnes P, Bowirrat A, Giordano J, Oscar-Berman M, Gold M: Sex, drugs, and rock ' $n$ ' roll: hypothesizing common mesolimbic activation as a function of reward gene polymorphisms. J Psychoactive Drugs. 2012, 44:38-55. 10.1080/02791072.2012.662112

26. Carnes PJ, Green BA, Merlo LJ, Polles A, Carnes S, Gold MS: PATHOS: a brief screening application for assessing sexual addiction. J Addict Med. 2012, 6:29-34.

10.1097/ADM.0b013e3182251a28

27. Hanson RK: Does Static-99 predict recidivism among older sexual offenders? . Sex Abuse. 2006, 18:343-355. 10.1007/s11194-006-9027-y

28. Weinstein A, Katz L, Eberhardt H, Cohen K, Lejoyeux M: Sexual compulsion - Relationship with sex, attachment and sexual orientation. J Behav Addict. 2015, 4: 22-26. 10.1556/JBA.4.2015.1.6

29. Chung WS, Lim SM, Yoo JH, Yoon H: Gender difference in brain activation to audio-visual sexual stimulation; do women and men experience the same level of arousal in response to the same video clip?. Int J Impot Res. 2013, 25:138-142. 10.1038/ijir.2012.47

30. Rupp HA, Wallen K: Sex differences in response to visual sexual stimuli: a review . Arch Sex Behav. 2008, 37:206-218. 10.1007/s10508-007-9217-9

31. Hanson RK, Harris AJ, Helmus L, Thornton D: High-risk sex offenders may not be high risk forever. J Interpers Violence. 2014, 29:2792-813. 10.1177/0886260514526062

32. Reid RC, Cyders MA, Moghaddam JF Fong TW: Psychometric properties of the Barratt Impulsiveness Scale in patients with gambling disorders, hypersexuality, and methamphetamine dependence. Addict Behav. 2014, 39:1640-1645.

10.1016/j.addbeh.2013.11.008

33. Reid RC, Carpenter BN, Hook JN, Garos S, Manning JC, Gilliland R, Cooper EB, McKittrick H, Davtian M, Fong T: Report of findings in a DSM-5 field trial for hypersexual disorder . J Sex Med. 2012, 9:2868-2877. 10.1111/j.1743-6109.2012.02936.x

34. Garcia FD, Thibaut F: Sexual addictions. Am J Drug Alcohol Abuse. 2010, 36:254-260. 10.3109/00952990.2010.503823

35. Reid RC, Bramen JE, Anderson A, Cohen MS: Mindfulness, emotional dysregulation, impulsivity, and stress proneness among hypersexual patients. J Clin Psychol. 2014, 70:313321. 10.1002/jclp.22027

36. Holder MK, Hadjimarkou MM, Zup SL, Blutstein T, Benham RS, McCarthy MM, Mong JA: Methamphetamine facilitates female sexual behavior and enhances neuronal activation in the medial amygdala and ventromedial nucleus of the hypothalamus. Psychoneuroendocrinology. 2010, 35:197-208. 10.1016/j.psyneuen.2009.06.005

37. Spauwen LW, Niekamp AM, Hoebe CJ, Dukers-Muijrers NH: Drug use, sexual risk behaviour and sexually transmitted infections among swingers: a cross-sectional study in The Netherlands. Sex Transm Infect. 2015, 91:31-36. 10.1136/sextrans-2014-051626

38. Castelo-Branco C, Parera N, Mendoza N, Pérez-Campos E, Lete I, CEA group: Alcohol and drug abuse and risky sexual behaviours in young adult women. Gynecol Endocrinol. 2014, 30:581586. 10.3109/09513590.2014.910190

39. Jia ZJ, Yan SY, Bao YP, Lian Z, Zhang HR, Liu ZM: Sexual behavior differences between amphetamine-type stimulants users and heroin users. J Addict Med. 2013, 7:422-427. 10.1097/ADM.0b013e3182a952b2

40. Bruijnzeel AW: kappa-Opioid receptor signaling and brain reward function . Brain Res Rev. 2009, 
62:127-146. 10.1016/j.brainresrev.2009.09.008

41. Orsini CA, Ginton G, Shimp KG, Avena NM, Gold MS, Setlow B: Food consumption and weight gain after cessation of chronic amphetamine administration. Appetite. 2014, 78:76-80. 10.1016/j.appet.2014.03.013

42. Ibrahim C, Reynaert C: Hypersexuality in neurocognitive disorders in elderly people - a comprehensive review of the literature and case study. Psychiatr Danub. 2014, 26:36-40.

43. Vallejo-Medina P, Sierra JC: Effect of drug use and influence of abstinence on sexual functioning in a Spanish male drug-dependent sample: a multisite study. J Sex Med. 2013, 10:333-341. 10.1111/j.1743-6109.2012.02977.x

44. Baskerville TA, Douglas AJ: Dopamine and oxytocin interactions underlying behaviors: potential contributions to behavioral disorders. CNS Neurosci Ther. 2010, 16:e92-123. 10.1111/j.1755-5949.2010.00154.x

45. Riebe CJ, Lee TT, Hill MN, Gorzalka BBB: Precipitated withdrawal counters the adverse effects of subchronic cannabinoid administration on male rat sexual behavior. Neurosci Lett. 2010, 472:171-174. 10.1016/j.neulet.2010.01.079

46. Korda JB, Pfaus JG, Kellner CH, Goldstein I: Persistent genital arousal disorder (PGAD): case report of long-term symptomatic management with electroconvulsive therapy. J Sex Med. 2009, 6:2901-2909. 10.1111/j.1743-6109.2009.01421.x

47. Huang CJ, Liao HT, Yeh GC,Hung KL: Distribution of HLA-DQB1 alleles in patients with KleineLevin syndrome. J Clin Neurosci. 2012, 19:628-630. 10.1016/j.jocn.2011.08.020

48. Blum K, Noble EP, Sheridan PJ, Montgomery A, Ritchie T, Jagadeeswaran P, Nogami H, Briggs AH, Cohn JB: Allelic association of human dopamine D2 receptor gene in alcoholism . JAMA. 1990, 263:2055-2060. 10.1001/jama.263.15.2055

49. Blum K, Sheridan PJ, Wood RC, Braverman ER, Chen TJ, Cull JG, Comings DE: The D2 dopamine receptor gene as a determinant of reward deficiency syndrome. J R Soc Med. 1996, 89:396-400. $10.1177 / 014107689608900711$

50. Miller WB, Pasta DJ, MacMurray J, Chiu C, Wu H, Comings DE: Dopamine receptor genes are associated with age at first sexual intercourse. J Biosoc Sci. 1999, 31:43-54.

10.1017/S0021932099000437

51. Hamann S, Herman RA, Nolan CL, Wallen K: Men and women differ in amygdala response to visual sexual stimuli. Nat Neurosci. 2004, 7:411-416. 10.1038/nn1208

52. Quiñones-Jenab V: Why are women from Venus and men from Mars when they abuse cocaine? . Brain Res. 2006, 1126:200-203. 10.1016/j.brainres.2006.08.109

53. Noble EP, Blum K, Khalsa ME, Ritchie T, Montgomery, A Wood RC, Fitch RJ, Ozkaragoz T, Sheridan PJ, Anglin MD, Paredes A, Treiman LJ, Sparkes RS: Allelic association of the D2 dopamine receptor gene with cocaine dependence. Drug Alcohol Depend. 1993, 33:271-285. 10.1016/0376-8716(93)90113-5

54. Harrison PJ, Tunbridge EM: Catechol-O-methyltransferase (COMT): a gene contributing to sex differences in brain function, and to sexual dimorphism in the predisposition to psychiatric disorders. Neuropsychopharmacology. 2008, 33:3037-3045. 10.1038/sj.npp.1301543

55. Guo G, Tong Y: Age at first sexual intercourse, genes, and social context: evidence from twins and the dopamine D4 receptor gene. Demography. 2006, 43:747-769. 10.1353/dem.2006.0029

56. Bradley KC, Boulware MB, Jiang H, Doerge RW, Meisel RL, Mermelstein PG: Changes in gene expression within the nucleus accumbens and striatum following sexual experience. Genes Brain Behav. 2005, 4:31-44. 10.1111/j.1601-183X.2004.00093.x

57. Rao BS, Raju TR, Meti BL: Increased numerical density of synapses in CA3 region of hippocampus and molecular layer of motor cortex after self-stimulation rewarding experience. Neuroscience. 1999, 91:799-803. 10.1016/S0306-4522(99)00083-4

58. Heshmati M: Cocaine-induced LTP in the ventral tegmental area: new insights into mechanism and time course illuminate the cellular substrates of addiction. J Neurophysiol. 2009, 101:27352737. 10.1152/jn.00127.2009

59. Beaver KM, Wright JP, Walsh A: A gene-based evolutionary explanation for the association between criminal involvement and number of sex partners. Biodemography Soc Biol. 2008, 54:47-55. 10.1080/19485565.2008.9989131

60. Santtila P, Jern P, Westberg L, Walum H, Pedersen CT, Eriksson E, Sandnabba N: The dopamine transporter gene (DAT1) polymorphism is associated with premature ejaculation . J Sex Med. 2010, 7:1538-1546. 10.1111/j.1743-6109.2009.01696.x

61. Chen TJH, Blum K, Mathews D, Fisher L, Schnautz N, Braverman Er, Schoolfield J, Downs W, 
Blum SH, Mengucci J, Meshkin B, Arcuri V, Bajaj A, Waite RL, Comings DE: Preliminary association of both the Dopamine D2 Receptor (DRD2) [Taq1 A1 Allele] and the Dopamine Transporter (DAT1) [480 bp Allele] genes with pathological aggressive behavior, a clinical subtype of Reward Deficiency Syndrome (RDS) in adolescents. Gene Ther Mol Biol. 2007, 1:93112. Accessed: July 23, 2015: http://gtmb.org/pages/Vol11A/HTML/11._Chen_et_al,_93102.htm.

62. Burt SA, Mikolajewski AJ: Preliminary evidence that specific candidate genes are associated with adolescent-onset antisocial behavior. Aggress Behav. 2008, 34:437-445. 10.1002/ab.20251

63. Jóźków P, Słowińska-Lisowska M, Łaczmański Ł, Mędraś M: Polymorphic variants of neurotransmitter receptor genes may affect sexual function in aging males: data from the HALS study. Neuroendocrinology. 2013, 98:51-59. 10.1159/000350324

64. Sales JM, DiClemente RJ, Brody GH, Philibert RA, Rose E: Interaction between 5HTTLPR polymorphism and abuse history on adolescent African-American females' condom use behavior following participation in an HIV prevention intervention. Prev Sci. 2014, 15:257267. 10.1007/s11121-013-0378-6

65. Barrett CE, Keebaugh AC, Ahern TH, Bass CE, Terwilliger EF, Young LJ: Variation in vasopressin receptor (Avpr1a) expression creates diversity in behaviors related to monogamy in prairie voles. Horm Behav. 2013, 63:518-526. 10.1016/j.yhbeh.2013.01.005

66. Garcia JR, MacKillop J, Aller EL, Merriwether AM, Wilson DS, Lum JK: Associations between dopamine D4 receptor gene variation with both infidelity and sexual promiscuity. PLoS One. 2010, 5:e14162. 10.1371/journal.pone.0014162

67. Daw J, Guo G: The influence of three genes on whether adolescents use contraception, USA 1994-2002. Popul Stud (Camb). 2011, 65:253-271. 10.1080/00324728.2011.598942

68. Emanuele E, Brondino N, Pesenti S, Re S, Geroldi D: Genetic loading on human loving styles . Neuro Endocrinol Lett. 2007, 28:815-821.

69. Matsuda KI: Epigenetic changes in the estrogen receptor $\alpha$ gene promoter: implications in sociosexual behaviors. Front Neurosci. 2014, 8:344. 10.3389/fnins.2014.00344

70. Rice WR, Friberg U, Gavrilets S: Homosexuality via canalized sexual development: a testing protocol for a new epigenetic model. Bioessays. 2013, 35:764-770. 10.1002/bies.201300033

71. Gundersen B: Pair-bonding through epigenetics. Nat Neurosci. 2013, 16:779. 10.1038/nn0713779

72. Wang H, Duclot F, Liu Y, Wang Z, Kabbaj M: Histone deacetylase inhibitors facilitate partner preference formation in female prairie voles. Nat Neurosci. 2013, 16:919-924. 10.1038/nn.3420

73. Zeh JA, Zeh DW: Maternal inheritance, epigenetics and the evolution of polyandry. Genetica. 2008, 134:45-54. 10.1007/s10709-007-9192-z

74. Addad M, Lesiau A: Extraversion, neuroticism, immoral judgment and criminal behaviour. Med Law. 1989, 8:611-622.

75. Brodie R: Virus of the Mind: The New Science of the Meme . Hay House, Inc, New York, NY; 1996, pp 66.

76. Hernnstein R, Murray C: The Bell Curve: Intelligence and Class Structure in American Life . The Free Press, New York, NY; 1994.

77. Smillie LD, Cooper AJ, Proitsi P, Powell JF, Pickering AD: Variation in DRD2 dopamine gene predicts extraverted personality. Neurosci Lett. 2010, 468:234-327.

10.1016/j.neulet.2009.10.095

78. Comings DE : The Gene Bomb. Does Higher Education and Advanced Technology Accelerate the Selection of Genes for Learning Disorders, ADHD, Addictive and Disruptive Behaviors?. Hope Press, Duarte CA; 1996.

79. Comings DE: The Adolescent Problem Behavior Syndrome. The Gene Bomb. Does Higher Education and Advanced Technology Accelerate the Selection of Genes for Learning Disorders, ADHD, Addictive and Disruptive Behaviors?. Hope Press , Duarte CA; 1996. pp 91-94.

80. Comings DE: Gene selection. The Gene Bomb. Does Higher Education and Advanced Technology Accelerate the Selection of Genes for Learning Disorders, ADHD, Addictive and Disruptive Behaviors?. Hope Press, Duarte CA; 1996. pp 89-90.

81. Comings DE : The Berkeley Study. The Gene Bomb. Does Higher Education and Advanced Technology Accelerate the Selection of Genes for Learning Disorders, ADHD, Addictive and Disruptive Behaviors?. Hope Press, Duarte California; 1996. pp 105-210.

82. Borsten J: Malibu Beach Recovery Diet Cookbook. Vidov Publishing Inc, Malibu, CA; 2015.

83. Derbyshire KL, Grant JE: Compulsive sexual behavior: A review of the literature . J Behav Addict. 
2015, 4: 37-43. 10.1556/2006.4.2015.003

84. Nirenberg MJ: Dopamine agonist withdrawal syndrome: implications for patient care. Drugs Aging. 2013, 30:587-592. 10.1007/s40266-013-0090-z

85. Grant JE, Brewer JA, Potenza MN: The neurobiology of substance and behavioral addictions . CNS Spectr. 2006, 11:924-930.

86. Sakata K, Duke SM: Lack of BDNF expression through promoter IV disturbs expression of monoamine genes in the frontal cortex and hippocampus. Neuroscience. 2014, 260:265-75. 10.1016/j.neuroscience.2013.12.013

87. Blum K, Liu Y, Wang W, Wang Y, Zhang Y, Oscar-Berman M, Smolen A, Febo M, Han D, Simpatico T, Cronjé FJ, Demetrovics Z, Gold MS: rsfMRI effects of KB220Z ${ }^{\mathrm{TM}}$ on neural pathways in reward circuitry of abstinent genotyped heroin addicts. Postgrad Med. 2015, 127:232-241.

88. McLaughlin T, Blum K, Oscar-Berman M, Febo M, Demetrovics Z, Agan G, Fratantonio J, Gold

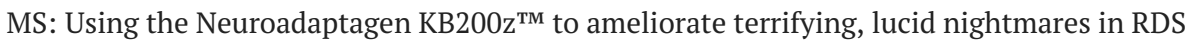
patients: the role of enhanced, brain-reward, functional connectivity and dopaminergic homeostasis. J Reward Defic Syndr. 2015, 1:24-35. 10.17756/jrds.2015-006

89. Blum K, Thanos PK, Badgaiyan RD, Febo M, Oscar-Berman M, Fratantonio J, Demotrovics Z, Gold MS: Neurogenetics and gene therapy for reward deficiency syndrome: are we going to the Promised Land?. Expert Opin Biol Ther. 2015, 5:973-985. 10.1517/14712598.2015.1045871

90. Joranby L, Pineda-Frost KY, Gold MS: Addiction to food and brain reward systems . Sexual Addiction \& Compulsivity. 2005, 12:201-217. 10.1080/10720160500203765

91. Edge PJ, Gold MS: Drug withdrawal and hyperphagia: lessons from tobacco and other drugs . Curr Pharm Des. 2011, 17:1173-1179. 10.2174/138161211795656738 